\title{
Evolution of Nutritional Status after Early Nutritional Management in COVID-19 Hospitalized Patients
}

\author{
Dorothée Bedock $^{1}$, Julie Couffignal ${ }^{1}$, Pierre Bel Lassen ${ }^{1,2}$, Leila Soares ${ }^{1} \oplus$, Alexis Mathian ${ }^{3}$, Jehane P. Fadlallah ${ }^{3}$, \\ Zahir Amoura ${ }^{3}$, Jean-Michel Oppert ${ }^{1, *}$ and Pauline Faucher ${ }^{1}$ (D) \\ 1 Center for Research on Human Nutrition Ile-de-France (CRNH IdF), Nutrition Department, Institute of \\ Cardiometabolism and Nutrition (ICAN), Assistance Publique-Hôpitaux de Paris (AP-HP), Pitié-Salpêtrière \\ University Hospital, Sorbonne Université, 47-83 Boulevard de l'Hôpital, 75013 Paris, France; \\ dorothee.bedock@aphp.fr (D.B.); julie.couffignal@aphp.fr (J.C.); pierre.bellassen@aphp.fr (P.B.L.); \\ leila.soares@aphp.fr (L.S.); pauline.faucher@aphp.fr (P.F.) \\ 2 NutriOmics Team, INSERM UMRS U1166, Sorbonne Université, 75006 Paris, France \\ 3 French National Referral Center for Systemic Lupus Erythematosus, Antiphospholipid Antibody Syndrome \\ and Other Autoimmune Disorders, Centre d'Immunologie et des Maladies Infectieuses (CIMI-Paris), \\ Medicine Department, Inserm UMRS, Assistance Publique-Hôpitaux de Paris, Pitié-Salpêtrière University \\ Hospital, Sorbonne Université, 47-83 Boulevard de l'Hôpital, 75013 Paris, France; \\ alexis.mathian@aphp.fr (A.M.); jehane.fadlallah@aphp.fr (J.P.F.); zahir.amoura@aphp.fr (Z.A.) \\ * Correspondence: jean-michel.oppert@aphp.fr; Tel.: +331-4217-5779; Fax: +331-4217-5790
}

check for updates

Citation: Bedock, D.; Couffignal, J.; Bel Lassen, P.; Soares, L.; Mathian, A.; Fadlallah, J.P.; Amoura, Z.; Oppert,

J.-M.; Faucher, P. Evolution of Nutritional Status after Early Nutritional Management in COVID-19 Hospitalized Patients. Nutrients 2021, 13, 2276. https:// doi.org/10.3390/nu13072276

Academic Editor: Ina Bergheim

Received: 18 May 2021

Accepted: 23 June 2021

Published: 30 June 2021

Publisher's Note: MDPI stays neutral with regard to jurisdictional claims in published maps and institutional affiliations.

Copyright: (c) 2021 by the authors. Licensee MDPI, Basel, Switzerland. This article is an open access article distributed under the terms and conditions of the Creative Commons Attribution (CC BY) license (https:// creativecommons.org/licenses/by/ $4.0 /)$

\begin{abstract}
Background \& Aims: SARS-CoV2 infection is associated with an increased risk of malnutrition. Although there are numerous screening and nutritional management protocols for malnutrition, only few studies have reported nutritional evolution after COVID-19. The objectives of this study were to describe the evolution of nutritional parameters between admission and 30 days after hospital discharge, and to determine predictive factors of poor nutritional outcome after recovery in adult COVID-19 patients. Methods: In this observational longitudinal study, we report findings after discharge in 91 out of 114 patients initially admitted for COVID-19 who received early nutritional management. Nutritional status was defined using GLIM criteria and compared between admission and day 30 after discharge. Baseline predictors of nutritional status at day 30 were assessed using logistic regression. Results: Thirty days after discharge, $28.6 \%$ of patients hospitalized for COVID-19 were malnourished, compared to $42.3 \%$ at admission. Half of malnourished patients (53\%) at admission recovered a normal nutritional status after discharge. Weight trajectories were heterogeneous and differed if patients had been transferred to an intensive care unit (ICU) during hospitalization $(p=0.025)$. High oxygen requirement during hospitalization (invasive ventilation $p=0.016$ (OR 8.3 [1.6-61.2]) and/or oxygen therapy over $5 \mathrm{~L} / \mathrm{min} p=0.021$ (OR 3.2 [1.2-8.9]) were strong predictors of malnutrition one month after discharge. Conclusions: With early nutritional management, most patients hospitalized for COVID-19 improved nutritional parameters after discharge. These findings emphasize the importance of nutritional care in COVID-19 patients hospitalized in medicine departments, especially in those transferred from ICU.
\end{abstract}

Keywords: COVID-19; malnutrition; pneumonia; SARS-Cov2; albumin; nutritional management

\section{Introduction}

The recently described SARS-Cov2 infection (COVID-19) is responsible of severe pneumonia and high mortality rate. Several risk factors for severe COVID-19 have been identified including older age, male gender, metabolic comorbidities, but also malnutrition [1,2]. Correlation between nutritional status and severity or mortality of viral pneumonia had been described since the times of the 1918 influenza pandemic and more recently in other viral pneumonia including H1N1 virus [3,4]. Patients affected by COVID19 have been shown to be at high risk of malnutrition [5-8]. Indeed, using composite nutritional scores such as the Nutrition Risk Screening tool (NRS-2002) or the Controlling 
Nutritional Status (CONUT) score, the risk of COVID-19 related malnutrition has been estimated to be between 77 and $88 \%[6,8,9]$. Moreover, in a few recent studies using strictly defined anthropometric parameters based on GLIM criteria to define nutritional status [10], the prevalence of malnutrition in patients hospitalized for SARS-CoV2 was as high as 40 to $50 \%[8,11]$.

Origins of malnutrition in COVID-19 patients is likely because of reduced food intake, increased digestive and cutaneous losses (diarrhea, vomiting, sweating), olfactory and gustatory dysfunctions, hyper catabolism due to high level of inflammation and muscle wasting [10]. It is known that in hospitalized patients for medical or surgical disease, whatever they are, malnutrition is associated with short-term complications: greater hospital mortality, more frequent readmissions and longer hospital stays [12,13]. Unfavorable nutritional status may also affect long-term functional outcomes as described in survivors of acute respiratory distress syndrome (loss of muscle mass and gain of fat mass) [14]. Currently, little is known about consequences of malnutrition and the effects of nutritional care in COVID-19 patients.

Scientific societies in the field of nutrition have proposed protocols for early screening and management of malnutrition in patients hospitalized for COVID-19 [15-18]. However, only one study [19] has described short-term changes in nutritional status after nutritional management in such patients. To investigate further the evolution of malnutrition in COVID-19 patients, we implemented in April 2020 in our university hospital setting a nutritional protocol for care of patients seen during the first wave of the epidemics.

The objectives of the present study were to assess the effects of early nutritional management in hospitalized adult patients with COVID-19, comparing the prevalence and severity of malnutrition before and 30 days after hospital discharge. We then investigated the evolution of nutritional parameters one month after hospital discharge of these patients. Finally, we searched predictive factors of poor nutritional outcome after COVID-19 recovery.

\section{Materials \& Methods}

\subsection{Study Population}

This observational longitudinal study included all adult COVID-19 patients admitted to the E3M Institute at Pitié-Salpêtrière hospital (Assistance-Publique-Hôpitaux de Paris, Paris, France) from March 21st 2020 to April 24th 2020. Patients were admitted from the emergency department, medical units or intensive care units [6]. Confirmed SARS-Cov2 infection was defined by a positive result of real-time reverse-transcriptasepolymerase-chain-reaction (RT-PCR) assay from nasal and pharyngeal swab specimens and/or evocative thoracic CT-scan damage. The protocol was approved by the Ethical Research Committee of Sorbonne University (Paris, France) (CER-2020-71). All data were collected in the context of care. Therefore, in accordance with French law (including the GPRD), an informed consent from the patient was not sought. Patients were informed that data from their medical records might be used for research in accordance with privacy rules and that they could express their refusal. No patient opposed.

A total of 114 COVID-19 patients were hospitalized and had complete nutritional data during that time period. Among these, 18 were admitted from an intensive care unit (ICU) whereas 96 were admitted as a first line of care in our standard medical unit. Six (5.3\%) died during their stay and $17(14.9 \%)$ were still hospitalized at follow-up. The present study reports the follow-up findings in 91 out of 114 patients (i.e., $78.8 \%$ ) who were examined 30 days after hospital discharge. Mean length of stay was 9.7 days $[1 ; 34]$.

\subsection{Nutritional Assessment}

During hospitalization, data on last known weight (i.e., weight within the past 6 months before admission for COVID-19, referred to in the text as "usual weight") and height were self-reported by patients. Actual weight was measured on calibrated scales during their hospital stay allowing to calculate the percentage of weight loss from usual weight 
defined as ((usual weight-measured weight)*100)/usual weight. BMI was calculated as measured weight $(\mathrm{kg})$ divided by height (meter) squared. Albumin and transthyretin levels were measured at admission by routine lab procedures.

Diagnosis of malnutrition according to the GLIM criteria requires at least one etiologic criterion among reduced food intake or assimilation, inflammation or disease burden, and at least one phenotypic criterion among non-volitional weight loss, low BMI and reduced muscle mass [10]. In our setting, we considered that an etiologic criterion of malnutrition was always present due to COVID-19-induced inflammation. Additionally, in most cases, reduced food intake or assimilation, the other etiologic criterion, was present due to COVID-19 specific symptoms (anosmia, dysgueusia, nausea, vomiting, diarrhea). Phenotypic criteria were assessed using BMI and \% weight loss from usual weight. We also used the GLIM criteria to categorize the severity of malnutrition [10]. Hospital registered dietitians performed individualized prescription when the patient did not eat the entire meal tray presented for lunch or dinner or when he/she had lost weight.

Based on international recommendations [7-10], we followed a standardized, individualized and pragmatic approach for nutritional management [15-18]. We differentiated 3 situations: (i) No malnutrition when the patient consumed his/her entire tray and had not lost weight; (ii) moderate malnutrition if the patient consumed between half to $\frac{3}{4}$ of the tray and/or had lost 5 to $15 \%$ of his/her weight ; (iii) severe malnutrition if the patient consumed less than half of his/her tray and/or had lost more than $15 \%$ of his/her weight. All meals were systematically enriched with calories and proteins (to reach an average daily intake of $2160 \mathrm{kcal}$ instead of the usual $2000 \mathrm{kcal})$. Systematic prevention of refeeding syndrome was performed with either oral nutritional supplements or artificial nutrition in patients presenting moderate or severe malnutrition $[15,20]$.

Thirty days after hospital discharge, 91 patients came back for a follow-up examination. On that day, a detailed medical re-assessment was conducted by both an internist and a specialist in clinical nutrition including medical history since discharge, current medical treatment, course of COVID-19 hospitalization, COVID-19 complications and residual symptoms. In addition, blood sampling was performed for routine clinical biological assessment including albumin and transthyretin levels, and follow-up weight (digital scale) and standing height were measured. Percent weight variation from usual and from hospitalization weight were calculated respectively as ((follow-up weight *100)/usual weight) and ((follow-up weight * 100)/hospitalization weight). Body composition was assessed by bio-impedance analysis (Tanita TBF 300 GS; Tanita, France) [21]. Muscle function was assessed by handgrip testing (Electronic Hand Dynamometer EH101; Camry, Hong Kong). As performed during hospitalization of patients, nutritional status and malnutrition severity at follow-up were defined using GLIM criteria [10]. When needed after the medical examination, a dietary information sheet was provided to patients and further advice by a registered dietician was offered.

\subsection{Assessment of Severity of COVID-19}

Demographic features and comorbidities such as obesity, high blood pressure, diabetes, active smoking, chronic obstructive pulmonary disease, chronic kidney disease, chronic heart disease, known to be associated with COVID-19 severity [5,22] were screened during hospitalization. Following the same line, leucocytes, lymphocytes, polynuclear neutrophils, C-Reactive Protein (CRP), D-dimers levels were measured at admission [5,22]. Oxygen intake (L/min) at admission and during hospitalization, chest CT-scan pulmonary infiltrate, use of invasive or non-invasive ventilation, transfer to an intensive care unit (ICU) were also recorded to assess COVID-19 severity.

\subsection{Statistical Analyses}

Continuous variables were expressed as mean \pm SD. Categorical variables were expressed as absolute values and percentages. Continuous variables with a non-parametric distribution were log-transformed before analysis. Weight change from usual weight 
(before COVID-19) at the time of admission and 30 days after hospital discharge was analysed in a mixed linear model in relation with the initial parameters of severity of COVID-19. Linear regression with analysis of variance (ANOVA) for continuous variables and Pearson's chi-square $(\chi 2)$ test or Fisher's exact test for discrete variables were used to compare the different characteristics according to nutritional status. Relationships between baseline parameters and nutritional status 30 days after hospital discharge were investigated using a univariate logistic regression model. Measures of association between baseline variables and malnutrition at day 30 after discharge were performed by computing odds ratios [23]. Statistical tests were considered significant if $p<0.05$. All statistical analyses were conducted using R studio software version 1.2.1335 (http:/ / www.r-project. org, (accessed on 8 April 2019)).

\section{Results}

Table 1 presents the general characteristics and nutritional parameters of patients according to their GLIM nutritional status at day 30 after discharge. For the whole sample at admission, subjects were on average middle-aged but with a large age range (from 20 to 96 y). Subjects displayed several comorbidities: one-third with diabetes, one-fourth with chronic heart disease and one-fifth with chronic kidney disease. One-fourth of the sample was obese (BMI $\left.\geq 30 \mathrm{~kg} / \mathrm{m}^{2}\right)$. Thirty days after hospital discharge, 26 out of 91 patients $(28.6 \%)$ of patients were malnourished (and only 6 (6.6\%) severely malnourished). There was no significant difference in muscle mass and handgrip strength between well-nourished and malnourished patients at day 30 after discharge (Table 1).

Table 1. General characteristics and nutritional parameters of COVID-19 patients according to GLIM nutritional status 30 days after hospital discharge.

\begin{tabular}{|c|c|c|c|c|c|}
\hline & $\begin{array}{c}\text { [All] } \\
\mathrm{n}=\mathbf{9 1}\end{array}$ & $\begin{array}{c}0 \\
n=65\end{array}$ & $\begin{array}{c}1 \\
n=20\end{array}$ & $\begin{array}{c}2 \\
n=6\end{array}$ & $\begin{array}{c}p \\
\text { Value }\end{array}$ \\
\hline \multicolumn{6}{|l|}{ At admission } \\
\hline Age (years) & $57.7(15.6)$ & $57.5(14.4)$ & $54.4(18.3)$ & $70.2(14.9)$ & 0.09 \\
\hline Male, $n(\%)$ & $55(60.4)$ & $40(61.5)$ & $12(60.0)$ & $3(50.0)$ & 0.87 \\
\hline High blood pressure, $n(\%)$ & $46(50.5)$ & $5(53.8)$ & $8(40.0)$ & $3(50.0)$ & 0.55 \\
\hline Diabetes, $n(\%)$ & $30(33.0)$ & $24(36.9)$ & $6(30.0)$ & $0(0.0)$ & 0.22 \\
\hline Active smoking, $n(\%)$ & $4(4.8)$ & $1(1.6)$ & $3(18.8)$ & $0(0.0)$ & 0.05 \\
\hline Chronic obstructive pulmonary disease, $n(\%)$ & $7(7.7)$ & $4(6.2)$ & $1(5.0)$ & $2(33.3)$ & 0.08 \\
\hline Chronic kidney disease, $n(\%)$ & $16(17.6)$ & $11(16.9)$ & $4(20.0)$ & $1(16.7)$ & 0.89 \\
\hline Chronic heart disease, $n(\%)$ & $22(24.2)$ & $13(20.0)$ & $6(30.0)$ & $3(50.0)$ & 0.15 \\
\hline Weight at admission $(\mathrm{kg})$ & $76.3(17.3)$ & $77.8(14.5)$ & $75.0(21.5)$ & $64.3(25.8)$ & 0.18 \\
\hline Usual weight $(\mathrm{kg})$ & $80.4(18.0)$ & $80.9(15.0)$ & $81.3(21.8)$ & $71.0(32.4)$ & 0.42 \\
\hline Weight change from usual (\%) & $-5.4(5.7)$ & $-4.3(5.3)$ & $-8.0(5.9)$ & $-7.0(7.6)$ & 0.03 \\
\hline BMI $\left(\mathrm{kg} / \mathrm{m}^{2}\right)$ & $26.5(5.1)$ & $26.7(4.5)$ & $26.5(6.0)$ & $24.1(7.1)$ & 0.50 \\
\hline Obesity, $n\left(\%\right.$ BMI $\left.\geq 30 \mathrm{~kg} / \mathrm{m}^{2}\right)$ & $21(23.9)$ & $14(22.6)$ & $6(30.0)$ & $1(16.7)$ & 0.83 \\
\hline Albumin $(\mathrm{g} / \mathrm{L})$ & $30.3(5.6)$ & $30.0(5.7)$ & $30.8(6.0)$ & $32.2(1.7)$ & 0.62 \\
\hline Transthyretin (g/L) & $0.1(0.1)$ & $0.1(0.1)$ & $0.2(0.1)$ & $0.2(0.1)$ & 0.05 \\
\hline \multicolumn{6}{|l|}{ At 30 days after discharge } \\
\hline Weight $(\mathrm{kg})$ & $78.8(17.4)$ & $81.1(15.2)$ & $76.4(19.5)$ & $62.4(25.1)$ & 0.03 \\
\hline Weight change from usual (\%) & $-1.8(4.9)$ & $0.2(3.7)$ & $-5.7(2.9)$ & $-10.2(6.3)$ & $<0.01$ \\
\hline Weight change from admission (\%) & $2.7(4.3)$ & $3.6(3.8)$ & $1.4(5.0)$ & $-2.0(3.8)$ & $<0.01$ \\
\hline BMI $\left(\mathrm{kg} / \mathrm{m}^{2}\right)$ & $27.5(4.9)$ & $28.0(4.5)$ & $27.0(5.4)$ & $23.3(6.5)$ & 0.07 \\
\hline Obesity, $n\left(\%\right.$ BMI $\left.\geq 30 \mathrm{~kg} / \mathrm{m}^{2}\right)$ & $64(71.1)$ & 46 (71.9) & $13(65.0)$ & $5(83.3)$ & 0.73 \\
\hline Weight change from usual (kg) & $-1.6(4.4)$ & $0.1(3.0)$ & $-4.9(3.0)$ & $-8.6(7.7)$ & $<0.01$ \\
\hline Muscle mass (kg) & $55.0(12.3)$ & $55.9(12.3)$ & $53.2(11.1)$ & $49.4(18.5)$ & 0.45 \\
\hline Handgrip strength (kg) & $33.4(19.6)$ & $35.2(20.9)$ & $28.3(10.1)$ & $28.1(30.7)$ & 0.35 \\
\hline Albumin $(\mathrm{g} / \mathrm{L})$ & $42.1(4.7)$ & $42.2(5.1)$ & $41.4(3.6)$ & $43.0(4.7)$ & 0.75 \\
\hline Transthyretin (g/L) & $0.3(0.1)$ & $0.3(0.1)$ & $0.3(0.2)$ & $0.3(0.1)$ & 0.64 \\
\hline
\end{tabular}


Table 1. Cont.

\begin{tabular}{|c|c|c|c|c|c|}
\hline & $\begin{array}{c}\text { [All] } \\
\mathrm{n}=91\end{array}$ & $\begin{array}{c}0 \\
n=65\end{array}$ & $\begin{array}{c}1 \\
n=20\end{array}$ & $\begin{array}{c}2 \\
n=6\end{array}$ & $\begin{array}{c}p \\
\text { Value }\end{array}$ \\
\hline \multicolumn{6}{|l|}{ COVID parameters } \\
\hline Invasive ventilation, $n(\%)$ & $7(7.9)$ & $2(3.1)$ & $4(21.1)$ & $1(20.0)$ & 0.02 \\
\hline Non-invasive ventilation, $n(\%)$ & $20(22.2)$ & $11(16.9)$ & $7(36.8)$ & $2(33.3)$ & 0.11 \\
\hline $\mathrm{O} 2$ over $5 \mathrm{~L} / \mathrm{min}$ during COVID, $n(\%)$ & $7(7.7)$ & $1(1.5)$ & $5(25.0)$ & $1(16.7)$ & $<0.01$ \\
\hline Intensive Care Unit during COVID, $n(\%)$ & $30(33.0)$ & $18(27.7)$ & $10(50.0)$ & $2(33.3)$ & 0.16 \\
\hline CT pulmonary infiltrate over $50 \%, n(\%)$ & $9(11.5)$ & $7(12.5)$ & $1(5.9)$ & $1(20.0)$ & 0.45 \\
\hline Leucocytes $(\mathrm{G} / \mathrm{L})$ & $6.9(3.9)$ & $6.2(2.9)$ & $9.3(6.1)$ & $7.2(1.8)$ & 0.01 \\
\hline Lymphocytes (G/L) & $1.1(0.5)$ & $1.0(0.5)$ & $1.1(0.6)$ & $1.4(0.2)$ & 0.25 \\
\hline Polynuclear Neutrophils (G/L) & $5.3(3.8)$ & $4.6(2.6)$ & $8.1(6.7)$ & $5.2(1.9)$ & 0.01 \\
\hline $\mathrm{CRP}(\mathrm{mg} / \mathrm{L})$ & $91.1(73.3)$ & $100.3(77.5)$ & $63.5(50.2)$ & $61.2(56.4)$ & 0.16 \\
\hline $\mathrm{D}$ dimers $(\mu \mathrm{g} / \mathrm{L})$ & $1410.4(2035.1)$ & $1607.2(2291.4)$ & $795.0(818.7)$ & $986.7(371.0)$ & 0.45 \\
\hline
\end{tabular}

Results are expressed as mean (SD) for continuous data and $n(\%)$ for categorical data. $p$ values shown result from analysis of variance (ANOVA) for continuous data and Chi2 or Fisher's exact test for categorical data between the 3 categories of nutritional status. BMI: Body Mass Index.

There was high inter individual variability in weight change over time (Figure 1).

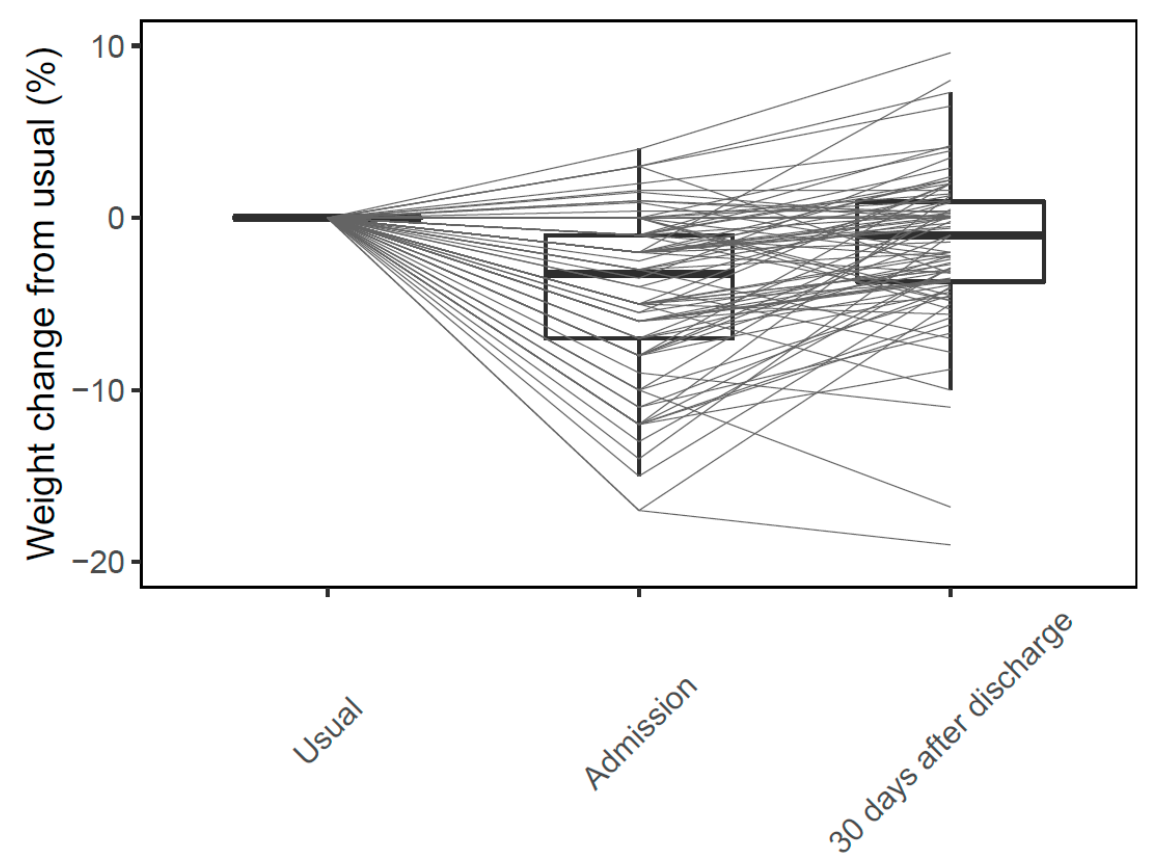

Figure 1. Individual weight change (\%) in COVID-19 patients between usual weight, hospital admission and 30 days after discharge.

At day 30 after discharge, weight change from admission in the whole sample was on average $+2.7 \%$ compared to admission. Weight change from admission differed significantly according to nutritional status at day 30 after discharge $(-2.0 \%,+1.4 \%$ and $+3.6 \%$ in severely, moderately malnourished and well-nourished patients, respectively). Weight trajectories differed according to whether patients had stayed in ICU during COVID-19 hospital management. On average, 30 days after hospital discharge, patients did not return to their usual weight. This was more pronounced in patients who had stayed in ICU during their hospitalization (Figure 2). 


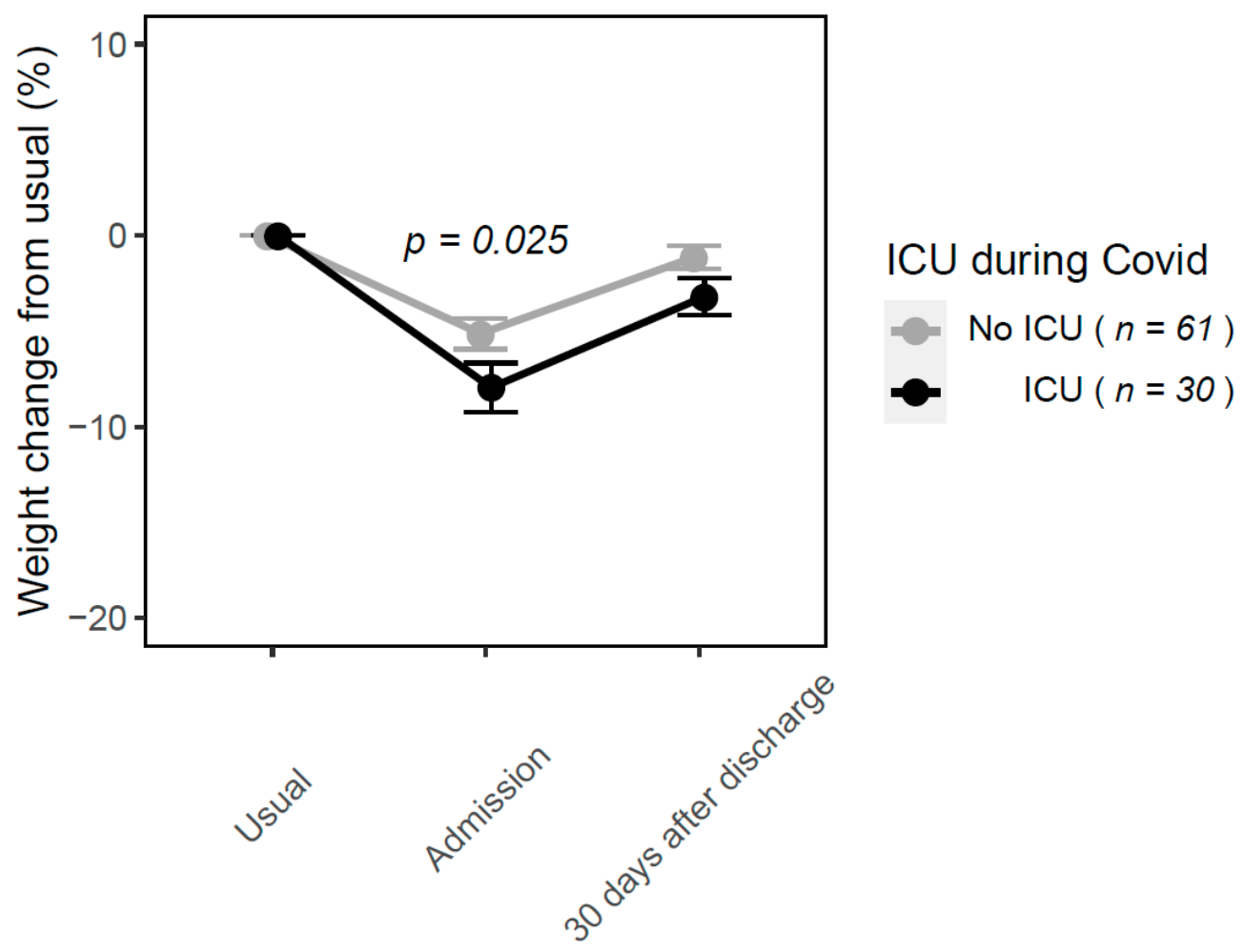

Figure 2. Mean weight change (\%) in COVID-19 patients depending on whether patients were transferred to ICU or not during hospital stay.

Changes in nutritional status according to GLIM criteria at admission and at day 30 after discharge are shown on Figure 3. At admission, $42.3 \%$ of the patients were malnourished (moderate or severe malnutrition combined). At day 30 after discharge, $53 \%$ of initially malnourished patients had normal nutritional status. Among those who had a normal nutritional status at admission, $14.3 \%$ were moderately malnourished at day 30 after discharge. Among patients who were moderately malnourished at admission, 2 patients became severely malnourished at day 30 after discharge (Figure 3).

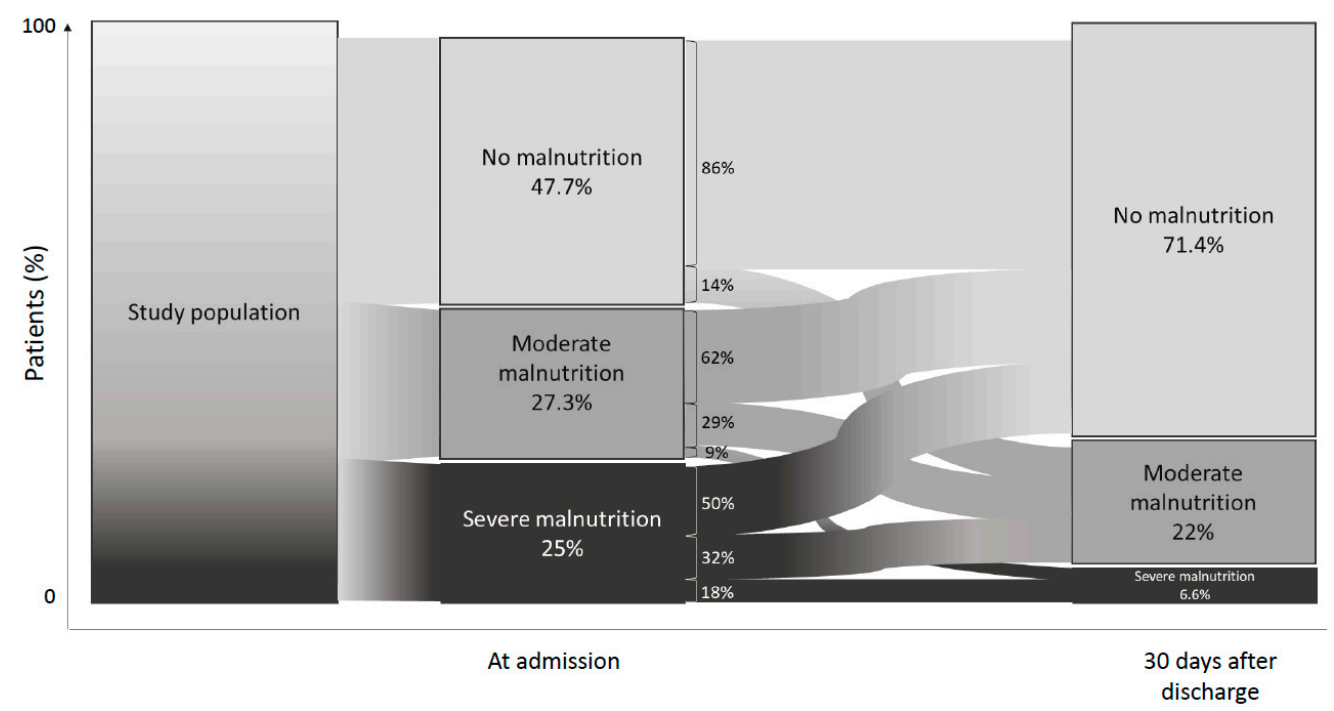

Figure 3. Evolution of nutritional status according to GLIM criteria between admission and 30 days after hospital discharge in COVID-19 patients. 
Patients malnourished compared to those with normal nutritional status at day 30 after hospital discharge had higher weight loss at admission, had received more frequently invasive ventilation and over $5 \mathrm{~L} / \mathrm{min} \mathrm{O}_{2}$ replacement therapy and had higher initial polynuclear neutrophils level. There was no significant difference in muscle mass and handgrip strength between well-nourished and malnourished patients at day 30 after discharge (Table 1). Use of invasive ventilation and receiving $\mathrm{O}_{2}$ over $5 \mathrm{~L} / \mathrm{min}$ were strong predictors of malnutrition 30 days after discharge (Table 2).

Table 2. Baseline predictors of malnutrition (moderate or severe) according to GLIM nutritional status 30 days after hospital discharge.

\begin{tabular}{ccc}
\hline Baseline Predictors of Malnutrition at Day 30 & OR [CI 95\%] & $p$ Value \\
\hline At admission & & 0.894 \\
Age & $1.0[0.9-1.0]$ & 0.735 \\
Male & $0.9[0.3-2.2]$ & 0.322 \\
High blood pressure & $0.6[0.2-1.6]$ & 0.209 \\
Diabetes & $0.5[0.2-1.4]$ & 0.058 \\
Active smoking & $9.5[1.1-197.8]$ & 0.391 \\
Chronic obstructive pulmonary disease & $2.0[0.4-9.7]$ & 0.794 \\
Chronic kidney disease & $1.2[0.3-3.6]$ & 0.146 \\
Chronic heart disease & $2.1[0.8-5.8]$ & 0.197 \\
Weight at admission & $1.0[0.9-1.0]$ & 0.634 \\
Usual weight & $1.0[0.9-1.0]$ & 0.013 \\
Weight change from usual & $1.1[1.0-1.2]$ & 0.524 \\
BMI & $1.0[0.9-1.1]$ & 0.663 \\
Obesity (BMI $\geq 30$ kg/m ${ }^{2}$ ) & $1.3[0.4-3.6]$ & 0.408 \\
Albumin & $1.0[1.0-1.1]$ & 0.061 \\
Transthyretin & $1.1[1.0-1.2]$ & \\
COVID parameters & & 0.016 \\
Invasive ventilation & $8.3[1.6-61.2]$ & 0.056 \\
Non-invasive ventilation & $2.8[1.0-7.9]$ & 0.021 \\
O2 over 5 L/min during COVID & $3.2[1.2-8.9]$ & 0.094 \\
Intensive Care Unit during COVID & $2.2[0.9-5.8]$ & 0.673 \\
CT pulmonary infiltrate over 50\% & $0.7[1.0-3.2]$ & 0.017 \\
Leucocytes & $1.2[1.0-1.4]$ & 0.190 \\
Lymphocytes & $1.9[0.7-5.3]$ & 0.024 \\
Polynuclear Neutrophils & $1.2[1.0-1.4]$ & 0.060 \\
CRP & $1.0[0.9-1.0]$ & 0.181 \\
\hline D dimers & $1.0[0.9-1.0]$ & \\
\hline
\end{tabular}

\section{Discussion}

In a series of 91 consecutive COVID-19 adult patients with various comorbidities, we were able to collect a range of phenotypical (BMI, weight loss) and biological (albumin, CRP) data at the beginning of hospitalization for COVID-19 and one month after hospital discharge. Our analysis reveals that $28.6 \%$ of patients hospitalized for COVID-19 were malnourished 30 days after hospital discharge, compared to $42.3 \%$ at admission. In parallel with early nutritional management, more than half of malnourished patients at admission recovered a normal nutritional status at day 30 after discharge. Weight trajectories were heterogeneous and differed according to whether patients had been transferred to ICU during hospital management. High oxygen requirement during hospitalization (invasive ventilation and/or oxygen therapy over $5 \mathrm{~L} / \mathrm{min}$ ) for COVID-19 were strong predictors of malnutrition one month after admission.

A main finding of this study is that almost half of patients with malnutrition at admission recovered a normal nutritional status 30 days after discharge. All patients received optimized nutritional management as adapted from international and French guidelines on nutritional screening and support [16-18], including systematic prevention of refeeding syndrome. These data demonstrate that recovering from malnutrition after 
COVID-19 is possible with early nutritional support. Nutritional evaluation after COVID19 is as yet not well defined. In a recent scoping review, Mechanick et al. did not find any research regarding nutrition risk assessment during outpatient follow-up after COVID19 [24]. Only one study (not included in that scoping review) presented nutritional data at follow-up of patients hospitalized for COVID-19: in 185 patients admitted for COVID-19 in an emergency department, De Lorenzo et al. reported that at a median follow-up of 23 days, $5.4 \%$ of patients were malnourished [19]. In our study, $28.6 \%$ of patients were malnourished 30 days after hospital discharge. We can formulate several explanations. First, De Lorenzo et al. used body weight change and Mini Nutritional Assessment (MNA) screening tool to assess malnutrition whereas we used strict GLIM criteria [10]. Moreover, our patients exhibited more comorbidities (such as diabetes, obesity, chronic organ failure), which are known independent risk factors of malnutrition [2,5,23,25-29]. Indeed, in our sample, $24.2 \%$ of patients suffered from chronic heart disease vs. $6.5 \%$ in the De Lorenzo study, $17.6 \%$ had chronic kidney disease vs. $2.4 \%$, and $7.7 \%$ had chronic obstructive pulmonary disease vs. $1.6 \%$. Furthermore, ICU transfer during a COVID-19 event is associated higher risk of malnutrition [11] and in our population, this was the case for 33\% of patients compared to $3.2 \%$ of hospitalized patients in the report of De Lorenzo et al. Another potential factor which could contribute to malnutrition at day 30 after discharge is the persistence of olfactory and gustatory dysfunctions. Indeed, smell and/or taste disturbances could lead to reduced food intake after general symptoms of COVID-19 resolution. Lechien et al. estimated that $56 \%$ of patients have persistent olfactory dysfunction over the days following the resolution of the COVID-19 general clinical manifestations [29].

An important finding of this study is that we were able to describe individual nutritional parameters (weight loss, weight trajectories, biological parameters) after the acute phase of COVID-19 infection. At admission, we observed in our patients a median weight loss of $-5.4 \%$ comparing to their (self-reported) usual weight. At day 30 after hospital discharge, even if individual weight trajectories were heterogeneous, patients had regained weight on average although they were still at $-1.8 \%$ of their usual weight. This is similar to the results shown by De Lorenzo et al. for hospitalized patients ( $-2 \%$ of the usual weight at follow-up) [19]. There was also a significant difference in weight trajectories according to whether patients had stayed in ICU during COVID-19 hospital management. Invasive ventilation is a strong predictor of malnutrition at follow-up and is only used in ICU. Another predictor of malnutrition was the use of $\mathrm{O} 2$ over $5 \mathrm{~L} / \mathrm{min}$, a sign of respiratory severity of COVID-19. Indeed, acute respiratory complications required ICU management and stay, which is associated with high risk of malnutrition because of hypercatabolism and food intake impairment, and with severe loss of skeletal muscle mass and function [16]. At last, in our study, all 91 patients had normal level of albumin one month after hospital discharge and two thirds improved (i.e., went from severe to moderate malnutrition) or normalized their nutritional status, which supports the efficiency of an early nutritional support in hospitalized COVID-19 patients. However, some patients had worsened their nutritional status, which can have several explanations: some had obesity and perhaps did not wish to regain their initial weight, some had psychological and/or social fragilities that occurred after their hospitalization, which could participate to their poor nutritional status at follow-up.

An important strength of our study in COVID-19 patients is that we were able to obtain follow-up nutritional data 30 days after hospitalization. We also used the specific metrics defined by GLIM [10] for malnutrition diagnosis at admission and 30 days after hospitalization even though these parameters are difficult to collect due to the lack of scales and in consideration of the hygienic precautions required in this particular setting [15]. Some limitations need to be mentioned. Our sample size possibly led to underestimate the prevalence of malnutrition 30 days after COVID-19 and thus, led to insufficient power to determine factors associated with malnutrition at day 30. We were not able to rigorously test the efficiency of our early nutritional management in the absence of a control group, which would have not been ethical in these conditions. Moreover, one of the phenotypic 
criteria defining malnutrition in GLIM is the loss of muscle mass and function. Even though we found no significant difference in muscle mass and handgrip strength between well-nourished and malnourished patients at day 30, it would have been of interest to have such data at admission. It is likely that, as previously observed in the context of other respiratory diseases, sarcopenia may heavily influence the course and outcomes of COVID-19 infection [30]. To be able to assess the effects of nutritional management on sarcopenia would be important in such setting [31,32].

\section{Conclusions}

In conclusion, we observed that recovering from malnutrition after COVID-19 hospitalization is possible with early nutritional management. In these patients hospitalized for COVID-19, weight trajectories differed when a transfer to ICU was needed during hospital management. Use of invasive ventilation and/or use of oxygen therapy over $5 \mathrm{~L} / \mathrm{min}$ during hospitalization for COVID-19 were strong predictors of malnutrition one month after discharge. These findings point to the importance of nutritional management during hospitalization and after hospital discharge for patients with severe respiratory COVID19, especially in those transferred from ICU. Further studies are needed to more fully assess the long-term impact of nutritional management during COVID-19 hospitalization, including sarcopenia.

Author Contributions: Conceptualization, D.B., P.F. and J.-M.O.; methodology, D.B., P.F. and J.-M.O.; software, P.B.L.; validation, P.F. and J.-M.O.; formal analysis, P.B.L.; investigation, D.B., P.B.L., J.C., L.S., J.P.F. and A.M.; resources, D.B.; data curation, D.B., P.B.L., A.M. and J.C.; writing-original draft preparation, D.B. and P.F.; writing—review and editing, D.B., P.F. and Z.A.; visualization, D.B.; supervision, D.B., P.F. and J.-M.O.; project administration, D.B.; funding acquisition: this research received no external funding. All authors have read and agreed to the published version of the manuscript.

Funding: This research received no external funding.

Institutional Review Board Statement: The study was conducted according to the guidelines of the Declaration of Helsinki, and approved by the Institutional Review Board (or Ethics Committee) of Sorbonne University (Paris, France) (CER-2020-71).

Informed Consent Statement: All data were collected in the context of care. Therefore, in accordance with French law (including the GPRD), an informed consent from the patient was not sought. Patients were informed that data from their medical records might be used for research in accordance with privacy rules and that they could express their refusal. No patient opposed.

Data Availability Statement: Data available on request due to restrictions eg privacy or ethical. The data presented in this study are available on request from the corresponding author. The data are not publicly available due to the format of consent.

Conflicts of Interest: The authors declare that they have no conflict of interest.

\section{References}

1. Wu, D.; Lewis, E.D.; Pae, M.; Meydani, S.N. Nutritional Modulation of Immune Function: Analysis of Evidence, Mechanisms, and Clinical Relevance. Front. Immunol. 2019, 9, 3160. [CrossRef]

2. Wang, D.; Hu, B.; Hu, C.; Zhu, F.; Liu, X.; Zhang, J.; Wang, B.; Xiang, H.; Cheng, Z.; Xiong, Y.; et al. Clinical Characteristics of 138 Hospitalized Patients With 2019 Novel Coronavirus-Infected Pneumonia in Wuhan, China. JAMA 2020, 323, 1061-1069. [CrossRef]

3. Short, K.; Kedzierska, K.; Van De Sandt, C.E. Back to the Future: Lessons Learned From the 1918 Influenza Pandemic. Front. Cell. Infect. Microbiol. 2018, 8, 343. [CrossRef] [PubMed]

4. Moser, J.-A.; Galindo-Fraga, A.; Ortiz-Hernández, A.A.; Gu, W.; Hunsberger, S.; Galán-Herrera, J.; Guerrero, M.L.; Ruiz-Palacios, G.M.; Beigel, J.H. The La Red ILI 002 Study Group Underweight, overweight, and obesity as independent risk factors for hospitalization in adults and children from influenza and other respiratory viruses. Influ. Other Respir. Viruses 2019, 13, 3-9. [CrossRef] [PubMed] 
5. Li, X.; Wang, L.; Yan, S.; Yang, F.; Xiang, L.; Zhu, J.; Shen, B.; Gong, Z. Clinical characteristics of 25 death cases with COVID-19: A retrospective review of medical records in a single medical center, Wuhan, China. Int. J. Infect. Dis. 2020, 94, 128-132. [CrossRef] [PubMed]

6. Wei, C.; Liu, Y.; Li, Y.; Zhang, Y.; Zhong, M.; Meng, X. Evaluation of the nutritional status in patients with COVID-19. J. Clin. Biochem. Nutr. 2020, 67, 116-121. [CrossRef] [PubMed]

7. Du, X.; Liu, Y.; Chen, J.; Peng, L.; Cheng, Z.; Wang, H.H.; Luo, M.; Jin, Y.; Zhao, Y. Comparison of the Clinical Implications among Two Different Nutritional Indices in Hospitalized Patients with COVID-19. medRxiv 2020. [CrossRef]

8. Pironi, L.; Sasdelli, A.S.; Ravaioli, F.; Baracco, B.; Battaiola, C.; Bocedi, G.; Brodosi, L.; Leoni, L.; Mari, G.A.; Musio, A. Malnutrition and nutritional therapy in patients with SARS-CoV-2 disease. Clin. Nutr. 2021, 40, 1330-1337. [CrossRef]

9. Allard, L.; Ouedraogo, E.; Molleville, J.; Bihan, H.; Giroux-Leprieur, B.; Sutton, A.; Baudry, C.; Josse, C.; Didier, M.; Deutsch, D.; et al. Malnutrition: Percentage and Association with Prognosis in Patients Hospitalized for Coronavirus Disease 2019. Nutrients 2020, 12, 3679. [CrossRef]

10. Cederholm, T.; Jensen, G.L.; Correia, M.I.T.D.; Gonzalez, M.C.; Fukushima, R.; Higashiguchi, T.; Baptista, G.; Barazzoni, R.; Blaauw, R.; Coats, A.; et al. GLIM criteria for the diagnosis of malnutrition-A consensus report from the global clinical nutrition community. Clin. Nutr. 2019, 38, 1-9. [CrossRef]

11. Bedock, D.; Lassen, P.B.; Mathian, A.; Moreau, P.; Couffignal, J.; Ciangura, C.; Poitou-Bernert, C.; Jeannin, A.-C.; Mosbah, H.; Fadlallah, J.; et al. Prevalence and severity of malnutrition in hospitalized COVID-19 patients. Clin. Nutr. ESPEN 2020, 40, 214-219. [CrossRef] [PubMed]

12. Agarwal, E.; Ferguson, M.; Banks, M.; Batterham, M.; Bauer, J.; Capra, S.; Isenring, E. Malnutrition and poor food intake are associated with prolonged hospital stay, frequent readmissions, and greater in-hospital mortality: Results from the Nutrition Care Day Survey 2010. Clin. Nutr. 2013, 32, 737-745. [CrossRef] [PubMed]

13. Hudson, L.; Chittams, J.; Griffith, C.; Compher, C. Malnutrition Identified by Academy of Nutrition and Dietetics/American Society for Parenteral and Enteral Nutrition Is Associated With More 30-Day Readmissions, Greater Hospital Mortality, and Longer Hospital Stays: A Retrospective Analysis of Nutrition A. J. Parenter. Enter. Nutr. 2018, 42, 892-897. [CrossRef]

14. Chan, K.S.; Mourtzakis, M.; Aronson Friedman, L.; Dinglas, V.D.; Hough, C.L.; Ely, E.W.; Morris, P.E.; Hopkins, R.O.; Needham, D.M. National Institutes of Health National Heart, Lung, and Blood Institute (NHLBI) Acute Respiratory Distress Syndrome (ARDS) Network. Evaluating Muscle Mass in Survivors of Acute Respiratory Distress Syndrome: A 1-Year Multicenter Longitudinal Study. Crit. Care Med. 2018, 46, 1238-1246. [CrossRef] [PubMed]

15. Caccialanza, R.; Laviano, A.; Lobascio, F.; Montagna, E.; Bruno, R.; Ludovisi, S.; Corsico, A.G.; Di Sabatino, A.; Belliato, M.; Calvi, M.; et al. Early nutritional supplementation in non-critically ill patients hospitalized for the 2019 novel coronavirus disease (COVID-19): Rationale and feasibility of a shared pragmatic protocol. Nutrition 2020, 74, 110835. [CrossRef]

16. Thibault, R.; Seguin, P.; Tamion, F.; Pichard, C.; Singer, P. Nutrition of the COVID-19 patient in the intensive care unit (ICU): A practical guidance. Crit. Care 2020, 24, 1-8. [CrossRef] [PubMed]

17. Thibault, R.; Quilliot, D.; Seguin, P.; Tamion, F.; Schneider, S.; Déchelotte, P. Stratégie de prise en charge nutritionnelle à l'hôpital au cours de l'épidémie virale Covid-19: Avis d'experts de la Société Francophone de Nutrition Clinique et Métabolisme (SFNCM) [Nutritional care at hospital during the Covid-19 viral epidemic: Expert opinion from the French-speaking Society for Clinical Nutrition and Metabolism (SFNCM)]. Nutr. Clin. Métab. 2020, 34, 97-104. [CrossRef]

18. Thibault, R.; Coëffier, M.; Joly, F.; Bohé, J.; Schneider, S.M.; Déchelotte, P. How the Covid-19 epidemic is challenging our practice in clinical nutrition-feedback from the field. Eur. J. Clin. Nutr. 2021, 75, 407-416. [CrossRef]

19. De Lorenzo, R.; Conte, C.; Lanzani, C.; Benedetti, F.; Roveri, L.; Mazza, M.G.; Brioni, E.; Giacalone, G.; Canti, V.; Sofia, V.; et al. Residual clinical damage after COVID-19: A retrospective and prospective observational cohort study. PLoS ONE 2020, 15. [CrossRef] [PubMed]

20. Barazzoni, R.; Bischoff, S.C.; Breda, J.; Wickramasinghe, K.; Krznarić, Ž.; Nitzan, D.; Pirlich, M.; Singer, P. ESPEN expert statements and practical guidance for nutritional management of individuals with SARS-CoV-2 infection. Clin. Nutr. Edinb. Scotl. 2020, 39, 1631-1638. [CrossRef]

21. Ciangura, C.; Bouillot, J.-L.; Lloret-Linares, C.; Poitou, C.; Veyrie, N.; Basdevant, A.; Oppert, J.-M. Dynamics of Change in Total and Regional Body Composition after Gastric Bypass in Obese Patients. Obesity 2010, 18, 760-765. [CrossRef] [PubMed]

22. Liu, W.; Tao, Z.-W.; Wang, L.; Yuan, M.-L.; Liu, K.; Zhou, L.; Wei, P.-F.; Deng, Y.; Liu, J.; Liu, H.-G.; et al. Analysis of factors associated with disease outcomes in hospitalized patients with 2019 novel coronavirus disease. Chin. Med. J. 2020, 133, 1032-1038. [CrossRef] [PubMed]

23. Ranganathan, P.; Aggarwal, R.; Pramesh, C.S. Common pitfalls in statistical analysis: Odds versus risk. Perspect. Clin. Res. 2015, 6, 222-224. [CrossRef] [PubMed]

24. Mechanick, J.I.; Carbone, S.; Dickerson, R.N.; Hernandez, B.J.D.; Hurt, R.T.; Irving, S.Y.; Li, D.Y.; McCarthy, M.S.; Mogensen, K.M.; Gautier, J.B.O.; et al. ASPEN COVID-19 Task Force on Nutrition Research. Clinical Nutrition Research and the COVID-19 Pandemic: A Scoping Review of the ASPEN COVID-19 Task Force on Nutrition Research. JPEN J. Parenter. Enter. Nutr. 2021, 45, 13-31. [CrossRef] [PubMed]

25. Zhou, F.; Yu, T.; Du, R.; Fan, G.; Liu, Y.; Liu, Z.; Xiang, J.; Wang, Y.; Song, B.; Gu, X.; et al. Clinical course and risk factors for mortality of adult inpatients with COVID-19 in Wuhan, China: A retrospective cohort study. Lancet 2020, 395, 1054-1062. [CrossRef] 
26. Ruan, Q.; Yang, K.; Wang, W.; Jiang, L.; Song, J. Clinical predictors of mortality due to COVID-19 based on an analysis of data of 150 patients from Wuhan, China. Intensive Care Med. 2020, 46, 846-848. [CrossRef]

27. Zhang, P.; He, Z.; Yu, G.; Peng, D.; Feng, Y.; Ling, J.; Wang, Y.; Li, S.; Bian, Y. The modified NUTRIC score can be used for nutritional risk assessment as well as prognosis prediction in critically ill COVID-19 patients. Clin. Nutr. 2020, 40, 534-541. [CrossRef]

28. Aghili, S.M.M.; Ebrahimpur, M.; Arjmand, B.; Shadman, Z.; Sani, M.P.; Qorbani, M.; Larijani, B.; Payab, M. Obesity in COVID-19 era, implications for mechanisms, comorbidities, and prognosis: A review and meta-analysis. Int. J. Obes. 2021, 45, 998-1016. [CrossRef]

29. Lechien, J.R.; Chiesa-Estomba, C.M.; De Siati, D.R.; Horoi, M.; Le Bon, S.D.; Rodriguez, A.; Dequanter, D.; Blecic, S.; El Afia, F.; Distinguin, L.; et al. Olfactory and gustatory dysfunctions as a clinical presentation of mild-to-moderate forms of the coronavirus disease (COVID-19): A multicenter European study. Eur. Arch. Otorhinolaryngol. 2020, 277, 2251-2261. [CrossRef]

30. Fedele, D.; De Francesco, A.; Riso, S.; Collo, A. Obesity, malnutrition, and trace element deficiency in the coronavirus disease (COVID-19) pandemic: An overview. Nutrition 2021, 81, 111016. [CrossRef]

31. Cruz-Jentoft, A.J.; Bahat, G.; Bauer, J.; Boirie, Y.; Bruyère, O.; Cederholm, T.; Cooper, C.; Landi, F.; Rolland, Y.; Sayer, A.A.; et al. Sarcopenia: Revised European consensus on definition and diagnosis. Age Ageing 2019, 48, 16-31. [CrossRef]

32. Brugliera, L.; Spina, A.; Castellazzi, P.; Cimino, P.; Arcuri, P.; Negro, A.; Houdayer, E.; Alemanno, F.; Giordani, A.; Mortini, P.; et al. Nutritional management of COVID-19 patients in a rehabilitation unit. Eur. J. Clin. Nutr. 2020, 74, 860-863. [CrossRef] [PubMed] 